\title{
Structure, energetics, and vibrational spectrum of $\mathrm{H}_{2} \mathrm{O}-\mathrm{HCl}$
}

\author{
Zdzisław Latajka ${ }^{\mathrm{a})}$ and Steve Scheiner ${ }^{\mathrm{b}), \mathrm{c})}$ \\ Department of Chemistry and Biochemistry, Southern Illinois University, Carbondale, Illinois 62901
}

(Received 29 May 1987; accepted 10 August 1987)

\begin{abstract}
$\mathrm{H}_{2} \mathrm{O}-\mathrm{HCl}$ is studied using a number of basis sets including 6-31G** and variants which are augmented by a diffuse $s p$ shell and a second set of $d$ functions on $\mathrm{O}$ and $\mathrm{Cl}$. Optimization of the geometry of the complex is carried out including explicitly electron correlation and counterpoise correction of the basis set superposition error (BSSE) at both the SCF and correlated levels. Correlation strengthens and shortens the $\mathrm{H}$ bond while BSSE correction leads to an opposite trend; these two effects are of different magnitude and hence cancel one another only partially. $\Delta H^{\circ}(298 \mathrm{~K})$ is calculated to be $-4.0 \mathrm{kcal} / \mathrm{mol}, 1 / 4$ of which is due to correlation. Formation of the complex causes the strong intensification and red shift of the $\mathrm{H}-$ $\mathrm{Cl}$ stretching band normally associated with $\mathrm{H}$ bonding, whereas the internal vibrations of $\mathrm{H}_{2} \mathrm{O}$ are very little affected, except for a doubling of the intensity of the symmetric stretch. With respect to the intermolecular modes, the bends of the proton donor are of higher frequency than those involving the acceptor. While these intermolecular bends are all of moderate intensity, comparable to the intramolecular modes, the H-bond stretch $v_{\sigma}$ is very weak indeed, consistent with a principle involving subunit dipoles. All calculated vibrational data are in excellent agreement with the spectra measured in solid inert gas matrices.
\end{abstract}

\section{INTRODUCTION}

One of the most interesting recent trends in vibrational spectroscopy has been directed towards intermolecular interactions and motions. In particular, enormous progress has been made in experimental study of $\mathrm{H}$-bonded systems in the gas phase. A range of spectroscopic techniques including molecular beam electric resonance, pulsed-nozzle Fourier transform microwave, and infrared laser are capable of providing valuable information concerning the structure and properties of a large number of $\mathrm{H}$-bonded complexes. ${ }^{1-4}$ This information is generally accessible from the mid-IR and Raman spectra, both exhibiting changes in the intramolecular force field induced directly by complexation or by coupling to intermolecular vibrations. ${ }^{5,6}$

The intermolecular modes can be studied directly by far infrared, low-frequency Raman, ${ }^{4,7}$ and incoherent inelastic neutron scattering spectroscopy. ${ }^{8}$ The most valuable information is extracted from gas phase measurements, free of perturbations from the environment. However, the low concentrations of the complexes and interference from the very intense rotational spectra occurring in the far-IR region makes reliable interpretation of the spectra of molecular complexes a challenging task. ${ }^{4}$ Indeed, a complete set of intermolecular vibrations has been determined for only a very limited number of $\mathrm{H}$-bonded complexes; viz. $\mathrm{H}_{2} \mathrm{O}-\mathrm{HF}$, $\mathrm{HCN}-\mathrm{HF}$, and $\mathrm{CH}_{3} \mathrm{CN}-\mathrm{HF}{ }^{9}$

Although suffering from another set of limitations, quantum mechanical calculations offer the opportunity of studying the entire vibrational spectrum of a given $\mathrm{H}$-bonded complex. Frequencies and intensities of intermolecular as

\footnotetext{
a) Permanent address: Institute of Chemistry, University of Wroclaw, 50383 Wroclaw, Poland.

b) Address correspondence to this author.

c) Recipient of NIH Research Career Development Award.
}

well as intramolecular vibrations can be calculated and analyzed. The suitability of this $a b$ initio approach to $\mathrm{H}$-bonded systems was first convincingly demonstrated by Curtiss and Pople $^{10}$ for $\mathrm{HCN}-\mathrm{HF},\left(\mathrm{H}_{2} \mathrm{O}\right)_{2}$, and ( $\left.\mathrm{HF}\right)_{2}$ with numerous additional applications subsequently. ${ }^{11}$ However, this early work was primarily restricted to frequencies with little attempt made to calculate the more difficult intensities. In addition, computational limitations forced many workers to make use of rather small and unpolarized basis sets. More recently, several groups have reexamined the problem within the context of modern computers and ab initio programs, calculating the frequencies and intensities of all vibrations with improved basis sets. ${ }^{12-15}$ Such calculations promise to be of great use in assisting experimentalists with band identification and elucidation of practical principles.

Hydrogen bonds of medium strength have provided a focus for a combined experimental and theoretical strategy. For example, $\mathrm{H}_{2} \mathrm{O}-\mathrm{HF}$ was among the first complexes whose IR spectrum was fully recorded in the gas phase ${ }^{9(a)}$ and was the subject of accurate $a b$ initio calculations, including the effects of electron correlation, upon the energetics, structure, and vibrational spectrum. ${ }^{16,17}$ Weak $\mathrm{H}$ bonds, such as $\mathrm{H}_{2} \mathrm{O}-\mathrm{HCl}$, on the other hand, are much less completely understood, despite their chemical importance. The geometry of this particular complex has been determined by gas phase rotational spectroscopy ${ }^{18}$ but no vibrational data was forthcoming. Clear identification of the vibrational bands has been limited to intramolecular modes in solid matrices. ${ }^{19-21}$ Previous quantum mechanical calculations ${ }^{17,22}$ have provided certain insights about the structure and energetics of this complex but have not considered the IR spectrum.

The present study focuses on the weak $\mathrm{H}$-bonded $\mathrm{H}_{2} \mathrm{O}-$ $\mathrm{HCl}$ complex with a number of objectives. First, we improve upon the prior calculations by application of improved basis 
TABLE I. Scaling factors $f$ and orbital exponents $\alpha$ for various basis set descriptions of $\mathrm{HCl}$.

\begin{tabular}{|c|c|c|c|c|c|c|c|}
\hline & \multicolumn{4}{|c|}{$\mathrm{Cl}^{\mathrm{N}}$} & \multicolumn{3}{|c|}{$\mathbf{H}$} \\
\hline & $f\left(3 s p_{i}\right)$ & $f\left(3 s p_{0}\right)$ & $\alpha_{s p}$ & $\alpha_{d}$ & $f\left(1 s_{i}\right)$ & $f\left(1 s_{0}\right)$ & $a_{p}$ \\
\hline $6-31 G * *$ & 1.0 & 1.0 & $\ldots$ & 0.750 & 1.200 & 1.150 & 1.100 \\
\hline$+v p^{s}$ & 0.996 & 1.043 & 0.077 & 0.770 & 1.132 & 1.214 & 1.135 \\
\hline$+\operatorname{VP}^{s}(2 d)^{s}$ & 0.996 & 1.043 & 0.077 & $0.997,0.206$ & 1.132 & 1.214 & 1.135 \\
\hline
\end{tabular}

-Scaling factors of $1 s$ and $2 s p$ shells of $\mathrm{Cl}$ were unchanged from unity by optimization.

sets and by rigorous correction of the basis set superposition artifact, a major source of error in both the geometry and complexation energy. More importantly, we supply for the first time a complete set of vibrational frequencies and intensities for this complex in the gas phase and compare our data with the experimental spectrum obtained in a solid matrix. We hope in this manner to critically evaluate the accuracy of an $a b$ initio approach and to arrive at an estimate of the perturbation caused by the matrix.

The next section lists the specifics of our basis sets and computational procedures which are tested and compared with experimental data for the isolated subunits in Sec. III. The structural and energetic aspects of the complex are described in the next section which includes the effects of correlation and counterpoise corrections. Section $V$ reports the complete vibrational analysis of the complex, comparing with the isolated subunits and experimental information.

\section{DETAILS OF CALCULATIONS}

$A b$ initio calculations were carried out using the GAUSSIAN-80 package of computer codes. ${ }^{23}$ Electron correlation was included via second order Møller-Plesset perturbation theory (MP2), keeping frozen the cores of heavy atoms. ${ }^{24}$

The smallest basis set applied to this system is 6-31G**, of standard split-valence type, containing polarization functions on all atoms. ${ }^{25}$ The two larger sets are derived from 6$31 \mathrm{G}^{* *}$ so as to improve the electronic distribution and polarizability of each subunit, provide a better framework for correlation, and reduce the basis set superposition error at primary and higher levels, as described in previous work. ${ }^{26,27}$ $+\mathrm{VP}^{s}$ adds a diffuse $s p$ shell to heavy atoms, followed by optimization of the SCF energy of the relevant subunits, here $\mathrm{H}_{2} \mathrm{O}$ and $\mathrm{HCl}$, with respect to the orbital exponents of all atoms. Further addition of a second set of $d$ functions to $O$ and $\mathrm{Cl}$, including subsequent reoptimization of both sets, leads to the basis set designated $+\operatorname{VP}^{s}(2 d)^{s}$. The optimized orbital parameters of $\mathrm{H}_{2} \mathrm{O}$ have been reported previously ${ }^{26}$; data for $\mathrm{HCl}$ are listed in Table $\mathrm{I}$.

Complete optimization of the geometry of $\mathrm{H}_{2} \mathrm{O}-\mathrm{HCl}$ was performed at the SCF level with the gradient procedures contained within GAUSSIAN-80 while MP2 optimizations required a stepwise procedure, holding fixed the internal geometry of $\mathrm{H}_{2} \mathrm{O}$ in its $\mathrm{SCF}$ configuration. Interaction energies

TABLE II. Computed properties of $\mathrm{H}_{2} \mathrm{O}$, all in a.u. unless otherwise indicated."

\begin{tabular}{|c|c|c|c|c|c|}
\hline & & $6-31 G^{* *}$ & $+V P^{s}$ & $+\mathrm{VP}^{s}(2 d)^{s}$ & Expt. \\
\hline$r(\mathrm{OH}), \AA$ & SCF & 0.943 & 0.943 & 0.943 & $0.9575^{b}$ \\
\hline$\theta(\mathrm{HOH}), \mathrm{deg}$ & SCF & 106.0 & 106.4 & 106.0 & $104.5^{b}$ \\
\hline \multirow[t]{2}{*}{ Energy } & SCF & -76.02361 & -76.03576 & -76.03885 & \\
\hline & MP2 & -0.19544 & -0.20956 & -0.22362 & \\
\hline \multirow[t]{2}{*}{$\mu, \mathrm{D}$} & SCF & 2.147 & 2.226 & 1.991 & $1.847^{\mathrm{c}}$ \\
\hline & MP2 & -0.085 & -0.048 & -0.036 & \\
\hline$\theta_{2 z}$ & SCF & -0.060 & -0.106 & -0.060 & $-0.097^{d}$ \\
\hline$\theta_{x x}$ & SCF & 1.73 & 1.92 & 1.93 & $1.96^{\mathrm{d}}$ \\
\hline $\boldsymbol{\Omega}_{\mathbf{z}}$ & SCF & 1.75 & 1.81 & 1.83 & \\
\hline $\boldsymbol{\Omega}_{y, z}$ & SCF & 0.95 & 1.16 & 1.35 & \\
\hline \multirow[t]{2}{*}{$\alpha_{z z}$} & SCF & 5.11 & 5.79 & 7.36 & $9.62^{\mathrm{e}}$ \\
\hline & MP2 & -0.07 & 0.33 & 0.45 & \\
\hline \multirow[t]{2}{*}{$a_{x x}$} & SCF & 7.02 & 7.23 & 8.23 & $10.01^{e}$ \\
\hline & MP2 & 0.04 & 0.14 & 0.25 & \\
\hline \multirow[t]{2}{*}{$\alpha_{y y}$} & SCF & 2.93 & 5.32 & 6.88 & $9.26^{\mathrm{e}}$ \\
\hline & MP2 & 0.06 & 0.97 & 1.15 & \\
\hline
\end{tabular}

\footnotetext{
Molecule lies in $x z$ plane, the $z$ axis coinciding with the $C_{2}$ rotation axis. The origin was taken as the center of mass. $\mu$ refers to dipole moment, $\theta$ to quadrupole, and $\Omega$ to octupole; the dipole polarizability is denoted $\alpha$.

${ }^{b}$ Reference 32.

'Reference 33.

${ }^{\mathrm{d}}$ Reference 34.

Estimated in Ref. 35 from various experimental sources.
} 
TABLE III. Computed properties of $\mathrm{HCl}$, all in a.u. unless otherwise indicated."

\begin{tabular}{|c|c|c|c|c|c|}
\hline & & $6-31 G^{* *}$ & $+V P^{s}$ & $+\mathrm{VP}^{S}(2 d)^{S}$ & Expt. \\
\hline$r(\mathrm{HCl}), \AA$ & $\begin{array}{l}\text { SCF } \\
\text { SCF }+ \text { MP2 }\end{array}$ & 1.266 & 1.269 & $\begin{array}{l}1.267 \\
1.274\end{array}$ & $1.274^{b}$ \\
\hline Energy & $\begin{array}{l}\text { SCF } \\
\text { MP2 }\end{array}$ & $\begin{array}{r}-460.06603 \\
-0.14932\end{array}$ & $\begin{array}{r}-460.06816 \\
-0.15146\end{array}$ & $\begin{array}{r}-460.07094 \\
-0.17212\end{array}$ & \\
\hline$\mu, D$ & $\begin{array}{l}\text { SCF } \\
\text { MP2 }\end{array}$ & $\begin{array}{r}1.469 \\
-0.049\end{array}$ & $\begin{array}{r}1.511 \\
-0.046\end{array}$ & $\begin{array}{r}1.231 \\
-0.040\end{array}$ & $1.093^{\mathrm{c}}$ \\
\hline$\theta_{z z}$ & $\mathrm{SCF}$ & 2.74 & 2.84 & 3.01 & $2.80^{\circ}$ \\
\hline$\Omega_{22 z}$ & SCF & 2.73 & 2.82 & 3.67 & \\
\hline$\alpha_{z z}$ & SCF & 12.90 & 12.64 & 16.02 & $21.1^{\mathrm{d}}$ \\
\hline$\alpha_{x x}$ & $\begin{array}{l}\text { MP2 } \\
\text { SCF }\end{array}$ & $\begin{array}{r}-0.15 \\
11.70\end{array}$ & $\begin{array}{r}-0.10 \\
11.09\end{array}$ & $\begin{array}{r}0.08 \\
14.50\end{array}$ & $19.6^{\mathrm{e}}$ \\
\hline & MP2 & -0.10 & -0.04 & 0.07 & \\
\hline
\end{tabular}

Molecular lies along the $z$ axis, the origin was taken as the center of mass.

${ }^{\mathrm{b}}$ Reference 32.

${ }^{\mathrm{E}}$ Reference 36.

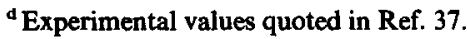

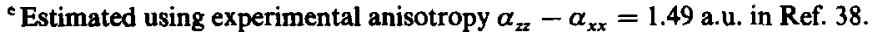

were computed as the difference in total energy between the complex and the isolated reference subunits. The basis set superposition error (BSSE) was calculated by the BoysBernardi counterpoise procedure $(\mathrm{CP})^{28}$ at both the SCF and MP2 levels, as recommended by numerous other workers. ${ }^{29}$

SCF and MP2 contributions to the dipole moment and dipole polarizability tensors of the isolated subunits were computed via the finite-field perturbation method, using a numerical differentiation based on a parabolic approximation for the dependence of the energy upon the electric field (increments of \pm 0.005 a.u.). Quadrupole and octupole moments were calculated at the SCF level using the molecular properties package contained within the MONSTERGAUSS program. ${ }^{30}$

The force constant matrix with respect to Cartesian atomic displacements was obtained by numerical differentiation ( \pm 0.01 a.u.) of the analytical gradient at the SCF equilibrium geometry. Diagonalization of the GF matrix led to the normal coordinates and their associated frequencies. ${ }^{31}$ The infrared intensity of each normal mode $Q$ was calculated as

$$
\begin{aligned}
A & =\left(\pi N_{0} / 3000 c\right)\left[\left(\frac{\partial \mu_{x}}{\partial Q}\right)^{2}+\left(\frac{\partial \mu_{y}}{\partial Q}\right)^{2}+\left(\frac{\partial \mu_{z}}{\partial Q}\right)^{2}\right] \\
& =974.9\left|\frac{\partial \mu}{\partial Q}\right|^{2},
\end{aligned}
$$

where $N_{0}$ is Avogadro's number and $c$ the speed of light. Equation (1) expresses the absolute integrated molar absorption coefficient $A$ in $\mathrm{km} / \mathrm{mol}$ when $\partial \mu / \partial Q$ is in units of $e$ a.u. ${ }^{-1 / 2}$.

\section{MONOMER PROPERTIES}

Before presenting our results for the $\mathrm{H}_{2} \mathrm{O}-\mathrm{HCl}$ complex, we begin with a comparison of the properties of the isolated subunits calculated with each of our basis sets. The data reported in the first two rows of Table II indicate the geometry of $\mathrm{H}_{2} \mathrm{O}$ is quite insensitive to basis set, with the calculated parameters within $0.01 \AA$ and $2^{\circ}$ of experiment.
The $\mathrm{HCl}$ bond length in Table III is also insensitive to basis set; good agreement with experiment arises after secondorder correlation has lengthened the bond somewhat.

The SCF energies in the following row obey the usual lowering with enlargement of basis set. Of particular note is the substantial increase in the MP2 energy of both $\mathrm{H}_{2} \mathrm{O}$ and $\mathrm{HCl}$ when a second set of $d$ functions is added to the basis, indicating an improved framework for description of correlation effects.

Due to the major role played by electrostatics in $\mathrm{H}$ bonding interactions, ${ }^{39}$ it is crucial that the theoretical approach accurately portray the multipole moments and polarizabilities of each subunit. From Tables II and III, it is clear that all basis sets exaggerate the dipole moment of $\mathrm{H}_{2} \mathrm{O}$ and $\mathrm{HCl}$ at the SCF level. However, addition of the second set of $d$ functions lessens this overestimate dramatically. The remaining discrepancy is not disturbing since SCF calculations of these two molecules, even using a basis set near the Hartree-Fock limit ${ }^{40}$ are uniformly too high. Following the further reduction in $\mu$ associated with correlation (a trend which agrees with calculations involving much larger basis sets), the MP2/ $+\operatorname{VP}^{S}(2 d)^{S}$ moments agree rather well with the experimental values (to within $8 \%$ ). With regard to the higher-order moments, they are not especially sensitive to the basis set although there is a general trend for the more extended sets to yield larger moments. The latter values are in reasonable agreement with the available experimental data. Based on recent calculations, correlation would not be expected to affect the quadrupole moments very much. ${ }^{40}$

The last rows of Tables II and III list the components of the dipole polarizability tensor which are all clearly underestimated when compared to the experimental values. This is not surprising in view of the very slow saturation of polarizabilities with respect to basis set as documented in the literature. ${ }^{41}$ Nevertheless, the smallest degree of underestimation is associated with our $+\operatorname{VP}^{s}(2 d)^{s}$ which is in error by about $15 \%\left(\mathrm{H}_{2} \mathrm{O}\right)$ and $25 \%(\mathrm{HCl})$ following correction by MP2.

In summary, the basis sets considered here appear to offer a reasonable framework for studying the $\mathrm{H}_{2} \mathrm{O}-\mathrm{HCl}$ 
TABLE IV. Calculated structural parameters of $\mathrm{H}_{2} \mathrm{O}-\mathrm{HCl}$ (in $\AA$ and deg).

\begin{tabular}{|c|c|c|c|c|c|}
\hline & \multirow{3}{*}{$\begin{array}{l}6-31 G^{* *} \\
\text { SCF } \\
\text { unc }\end{array}$} & \multirow{3}{*}{$\begin{array}{l}+\mathrm{VP}^{S} \\
\text { SCF } \\
\text { unc }\end{array}$} & \multicolumn{3}{|c|}{$+\operatorname{VP}^{s}(2 d)^{s}$} \\
\hline & & & \multirow{2}{*}{$\begin{array}{l}\text { SCF } \\
\text { unc }\end{array}$} & \multicolumn{2}{|c|}{$\mathrm{SCF}+\mathrm{MP} 2$} \\
\hline & & & & unc & corr \\
\hline$R(O \cdots \mathrm{Cl})$ & 3.250 & 3.303 & 3.369 & 3.235 & 3.281 \\
\hline$\theta(\mathrm{OClH})$ & 2.2 & 2.9 & 3.2 & 3.5 & 3.4 \\
\hline$\alpha^{\mathrm{a}}$ & 144.8 & 141.6 & 138.7 & 131.3 & 133.2 \\
\hline$r(\mathrm{HCl})$ & 1.277 & 1.278 & 1.275 & 1.286 & 1.289 \\
\hline$\Delta r(\mathrm{HCl})^{b}$ & 0.011 & 0.009 & 0.008 & 0.012 & 0.015 \\
\hline$r(\mathrm{OH})$ & 0.943 & 0.944 & 0.943 & $0.943^{c}$ & $0.943^{c}$ \\
\hline$\theta(\mathrm{HOH})$ & 107.1 & 107.1 & 106.7 & $106.7^{\mathfrak{c}}$ & $106.7^{\mathrm{c}}$ \\
\hline
\end{tabular}

Angle between $\mathrm{HOH}$ bisector and $\mathrm{O} \cdots \mathrm{Cl}$ axis.

${ }^{\mathrm{b}} r(\mathrm{HCl})_{\text {complex }}-r(\mathrm{HCl})_{\text {monomer }}$.

${ }^{c}$ Uncorrected SCF value.

complex. Geometries of the subunits agree favorably with experiment as do the multipole moments, especially in the case of $+\operatorname{VP}^{S}(2 d)^{s}$. The largest source of error arises from the polarizabilities which are underestimated by $15 \%-25 \%$ with the latter basis set. We can hence expect the contributions to the interaction energy from induction and dispersion to be underestimated as well.

\section{COMPLEX}

\section{A. Structure}

Table IV summarizes the optimized geometry of the $\mathrm{H}_{2} \mathrm{O}-\mathrm{HCl}$ complex obtained at various levels of theory. Focusing our attention first on the SCF results in the first three columns (uncorrected for BSSE), we see an elongation of the intermolecular separation $R(\mathrm{O} \cdots \mathrm{Cl})$ associated with enlargements of the basis set. This stretch is connected to a weakening of the interaction which is discussed in greater detail below. The $\theta(\mathrm{OClH})$ angle in the next row corresponds to the nonlinearity of the $\mathrm{H}$ bond which is less than $4^{\circ}$ in all cases.

$\alpha$, which measures the angle between the $\mathrm{HOH}$ bisector and the $\mathrm{O} \cdots \mathrm{Cl}$ axis, undergoes a modest reduction as the basis set is enlarged, taking the complex toward a more perpendicular arrangement. In order to analyze this trend, it must first be understood that the angle of around $140^{\circ}$ is due in large measure to a compromise between two different effects. ${ }^{42}$ The attraction between the dipole moment of water and the partial positive charge on the $\mathrm{H}$ of $\mathrm{HCl}$ pulls the $\mathrm{HOH}$ bisector away from $\mathrm{HCl}$, i.e., towards large values of $\alpha$ tending toward $180^{\circ}$. At the same time, since the out-ofplane component of the $\mathrm{H}_{2} \mathrm{O}$ quadrupole moment $\theta_{y y}$ is of negative sign, its attraction toward the hydrogen of $\mathrm{HCl}$ pulls the $\mathrm{HOH}$ in the opposite direction from the dipole, viz. toward lower $\alpha$. Enlarging the basis set both lowers $\mu$ and increases $\theta_{y y}$. Hence, the pull toward larger $\alpha$ is diminished while the force toward smaller $\alpha$ is enhanced; these two trends reinforce one another and a more perpendicular arrangement results. (An alternate explanation involving orbital overlap would invoke a greater separation of the two $O$ lone pairs with increasing basis set size. ${ }^{43}$ )
The next several rows of Table IV describe the internal geometries of the individual subunits which are relatively insensitive to basis set. $\Delta r(\mathrm{HCl})$ is defined as the stretching of this bond caused by $\mathrm{H}$-bond formation; i.e., the difference between $r(\mathrm{HCl})$ in the complex and in the isolated subunit. This stretching diminishes somewhat as the basis set is enlarged. The changes in the water geometry as a result of complex formation are negligible.

Turning now to the effects of electron correlation, comparison of the third and fourth columns of data in Table IV reveals a contraction of $0.13 \AA$ in $R(\mathrm{O} \cdots \mathrm{Cl})$, indicating a stabilization of the complex (see below). The MP2 value of $\alpha$ is some $7^{\circ}$ smaller than the SCF angle, consistent with the correlation-induced reduction in $\mu\left(\mathrm{H}_{2} \mathrm{O}\right)$ mentioned earlier. We note finally that inclusion of correlation results in a $50 \%$ increase in the stretch in $r(\mathrm{HCl})$ caused by $\mathrm{H}$-bond formation. The above findings are entirely consistent with our earlier calculations of the effects of correlation upon the structure of $\mathrm{H}_{2} \mathrm{O}-\mathrm{HCl}^{17}$

The last column in Table IV describes the geometry of the complex obtained when the optimization includes subtraction of the Boys-Bernardi counterpoise correction at both the SCF and MP2 levels. The principal effect is a $0.05 \AA$ increase in $R(\mathrm{O} \cdots \mathrm{Cl})$, due to the removal of the BSSE which represents a spurious attractive term. Our best estimate of the intermolecular distance is therefore $3.28 \AA, 0.07$ $\AA$ longer than the experimentally derived value. ${ }^{18}$ This discrepancy is not surprising since the calculated polarizability of the subunits is lower than the experimental results by some $25 \%$, leading to an underestimate of the induction and dispersion components of the interaction energy. A second factor is the termination of the perturbation expansion of the correlation energy at second order. Finally, our calculated equilibrium $R(\mathrm{O} \cdots \mathrm{Cl})$ represents $R_{e}$ while the experimental value corresponds to the vibration-averaged $\boldsymbol{R}_{0}$.

Previous experimental work ${ }^{18}$ has indicated the structure of $\mathrm{H}_{2} \mathrm{O}-\mathrm{HCl}$ belongs to the $C_{2 v}$ point group, i.e., $\alpha=180^{\circ}$ and $\theta(\mathrm{OClH})=0^{\circ}$, in contrast to our theoretical $C_{s}$ geometry. However, it must be borne in mind that the experimental structure is an average over ground-state vibrational motion whereas the theoretical geometry is a true 
TABLE V. Interaction energies and basis set superposition errors (all entries in $\mathrm{kcal} / \mathrm{mol}$ ).

\begin{tabular}{|c|c|c|c|c|}
\hline & \multirow[b]{2}{*}{$6-31 G^{* *}$} & \multirow[b]{2}{*}{$+V P^{s}$} & \multicolumn{2}{|c|}{$+\mathrm{VP}^{s}(2 d)^{s}$} \\
\hline & & & a & b \\
\hline & \multicolumn{4}{|c|}{$-\Delta E$} \\
\hline SCF & 6.16 & 5.09 & 3.97 & 3.85 \\
\hline MP2 & 1.20 & 1.19 & 1.30 & 1.58 \\
\hline \multirow{2}{*}{$\mathrm{SCF}+\mathrm{MP} 2$} & 7.36 & 6.28 & 5.27 & 5.42 \\
\hline & \multicolumn{4}{|c|}{ - BSSE } \\
\hline SCF & 0.85 & 0.48 & 0.09 & 0.11 \\
\hline \multirow{2}{*}{ MP2 } & 0.59 & 0.87 & 0.51 & 0.58 \\
\hline & \multicolumn{4}{|c|}{$-(\Delta E-B S S E)$} \\
\hline SCF & 5.31 & 4.61 & 3.88 & 3.74 \\
\hline MP2 & 0.61 & 0.32 & 0.79 & 1.00 \\
\hline $\mathrm{SCF}+\mathrm{MP2}$ & 5.92 & 4.94 & 4.67 & 4.74 \\
\hline
\end{tabular}

Geometry optimized at SCF level.

${ }^{b}$ Geometry optimized at MP2 level, including BSSE corrections.

equilibrium configuration. Taking our $\mathrm{MP} 2 /+\mathrm{VP}^{S}(2 d)^{s}$ geometry, corrected for BSSE, as a starting point, we calculated the barrier to inversion $\left(C_{s} \rightarrow C_{2 v} \rightarrow C_{s}\right)$ as 0.19 and $0.42 \mathrm{kcal} / \mathrm{mol}$ at the SCF and MP2 levels, respectively. When the barrier is this low, the ground vibrational wave function would be spread over a wide range of $\alpha$, leading to the observation of a time-averaged $C_{2 v}$ structure, as was illustrated earlier for $\mathrm{H}_{2} \mathrm{O}-\mathrm{HF}{ }^{17}$

\section{B. Interaction energy}

The energetic aspects of the complex are reported in Table $V$ where it may be seen from the first row that the SCF interaction energy decreases rather sharply as the basis set is enlarged from $6-31 \mathrm{G}^{* *}$ to $+\mathrm{VP}^{s}$ to $+\mathrm{VP}^{s}(2 d)^{s}$. The following row indicates the MP2 contribution to the interaction is quite insensitive to basis set, leaving the total interaction energies in the next row to reproduce the SCF trend.

The next two rows of Table $V$ contain the basis set superposition errors computed by the Boys-Bernardi counterpoise scheme. Whereas the SCF BSSE is nearly $1 \mathrm{kcal} / \mathrm{mol}$ for the $6-31 \mathrm{G}^{* *}$ basis set, this quantity has been reduced by an order of magnitude to negligible proportions with $+\operatorname{VP}^{S}(2 d)^{s}$. The MP2 BSSE, on the other hand, is much more resistant to these basis set enlargements, remaining above $0.5 \mathrm{kcal} / \mathrm{mol}$ for all sets. The very slow subsidence of the BSSE at correlated levels appears to be a general property as it has been observed for a range of different systems. ${ }^{29,44}$

Subtraction of the BSSE from $\Delta E$ leaves the corrected interaction energies listed in the last portion of Table $V$. The corrected values, like the uncorrected $\Delta E$, diminish with larger basis sets although not as dramatically. Our most reliable interaction energy, computed at the SCF + MP2 level with the $+\operatorname{VP}^{S}(2 d)^{S}$ basis set and including counterpoise correction of the BSSE, coupled to a geometry optimized at the same level, is $4.74 \mathrm{kcal} / \mathrm{mol}$. Of this total, $1.00 \mathrm{kcal} / \mathrm{mol}$ is due to correlation effects. Addition to this electronic contribution of zero-point vibrational energies, evaluated using the frequencies described below, yields a $\Delta E(0 \mathrm{~K})$ of -3.30 $\mathrm{kcal} / \mathrm{mol}$. Evaluating $\Delta H$ at $298 \mathrm{~K}$ requires translational, rotational, and vibrational energy corrections, as well as
TABLE VI. Infrared harmonic fundamental frequencies $\left(\mathrm{cm}^{-1}\right)$ and absolute intensities $(\mathrm{km} / \mathrm{mol})$ for water molecule.

\begin{tabular}{|c|c|c|c|c|c|c|}
\hline & $v_{1}$ & $A_{1}$ & $v_{2}$ & $A_{2}$ & $v_{3}$ & $A_{3}$ \\
\hline \multicolumn{7}{|c|}{$\mathrm{H}_{2} \mathrm{O}$} \\
\hline $6-31 G^{* *}$ & 4149 & 16 & 1770 & 104 & 4267 & 58 \\
\hline$+V P^{s}$ & 4129 & 25 & 1727 & 94 & 4242 & 85 \\
\hline$+\operatorname{VP}^{S}(2 d)^{S}$ & 4139 & 19 & 1759 & 103 & 4244 & 91 \\
\hline Ref. 45 & 3990 & 15 & 1720 & 99 & 4080 & 65 \\
\hline Expt: a & 3657 & 2.5 & 1595 & 76 & 3756 & 42 \\
\hline b & 3832 & 2.2 & 1648 & 67 & 3942 & 40 \\
\hline \multicolumn{7}{|c|}{$\mathrm{D}_{2} \mathrm{O}$} \\
\hline $6-31 G^{* *}$ & 2985 & 11 & 1283 & 52 & 3116 & 35 \\
\hline$+\mathrm{VP}^{s}$ & 2987 & 17 & 1268 & 50 & 3120 & 52 \\
\hline$+\operatorname{VP}^{S}(2 d)^{S}$ & 2994 & 13 & 1291 & 55 & 3120 & 54 \\
\hline Expt: b & & 2 & & 35 & & 25 \\
\hline
\end{tabular}

"Frequencies from Ref. 49; intensities from Ref. 46.

${ }^{b}$ Harmonic frequencies from Ref. 47; intensities from Ref. 48.

$\Delta P V$, leading finally to a value of $-3.96 \mathrm{kcal} / \mathrm{mol}$.

A number of SCF calculations in the literature have neglected to remove the BSSE, perhaps in the anticipation that retention of this artificial attractive property would in some sense compensate for the omission of correlation effects. The results in Table $\mathrm{V}$ suggest that this cancellation of errors is only true to a limited extent. For example, the SCF interaction energy with the $+\operatorname{VP}^{S}(2 d)^{s}$ basis set, and including geometry optimization at the SCF level, is $3.97 \mathrm{kcal} / \mathrm{mol}, 0.8$ less than the value obtained with correct treatment of correlation and BSSE. Nor do these two factors quantitatively cancel one another with respect to the intermolecular separation. As may be seen in Table IV, the uncorrected SCF value of $R(\mathrm{O} \cdots \mathrm{Cl})$ is $3.37 \AA, 0.09 \AA$ longer than the corrected MP2 distance.

\section{VIBRATIONAL FREQUENCIES AND INTENSITIES}

\section{A. Subunits}

Tables VI and VII list the frequencies and intensities we have calculated with each of our basis sets at the SCF level for the isolated $\mathrm{H}_{2} \mathrm{O}$ and $\mathrm{HCl}$ monomers and their deuterat-

TABLE VII. Infrared harmonic fundamental frequency $\left(\mathrm{cm}^{-1}\right)$ and absolute intensity $(\mathrm{km} / \mathrm{mol})$ for $\mathrm{HCl}$.

\begin{tabular}{|c|c|c|c|c|}
\hline & \multicolumn{2}{|c|}{$\mathrm{HCl}$} & \multicolumn{2}{|c|}{$\mathrm{DCl}$} \\
\hline & $v$ & $\boldsymbol{A}$ & $v$ & $A$ \\
\hline $\begin{array}{l}\text { 6-31G** } \\
+\mathrm{VP}^{s} \\
+\mathrm{VP}^{s}(2 d)^{s} \\
{[7 . s 6 p 2 d / 4 s 1 p]^{\mathrm{a}}} \\
\text { Expt }\end{array}$ & $\begin{array}{l}3178 \\
3174 \\
3174 \\
3141 \\
2990^{\mathrm{b}} \\
3042^{\mathrm{d}}\end{array}$ & $\begin{array}{l}34 \\
42 \\
57 \\
56 \\
39^{\mathbf{c}}\end{array}$ & $\begin{array}{l}2287 \\
2284 \\
2284 \\
2260\end{array}$ & $\begin{array}{l}18 \\
22 \\
30 \\
29\end{array}$ \\
\hline
\end{tabular}

${ }^{a}$ Basis set from Ref. 50 plus additional $s$ and $p$ functions $\left(\alpha_{s}=0.0554\right.$; $\left.\alpha_{p}=0.125\right)$ on $\mathrm{Cl}$ and $s$ on $\mathrm{H}\left(\alpha_{s}=0.0302\right)$. Exponents of polarization functions were optimized at SCF level: $\alpha_{d}(\mathrm{Cl})=1.147,0.280 ; \alpha_{p}(\mathrm{H})$ $=0.75$.

${ }^{b}$ From Ref. 51.

${ }^{\circ}$ Quoted in Ref. 52.

d Harmonic frequency from Ref. 53. 
ed derivatives. The data reported were obtained using the harmonic approximation and no attempt has been made to "scale" the SCF frequencies. $v_{1}, v_{2}$, and $v_{3}$ for water correspond, respectively, to the symmetric $\mathrm{O}-\mathrm{H}$ stretch, $\mathrm{HOH}$ bending, and the asymmetric stretch.

Scanning down any given column of Table VI, the dependence of the spectroscopic data upon basis set may be seen to be rather small. The frequencies vary by $40 \mathrm{~cm}^{-1}$ or less, with the intensities changing by less than a factor of 2; the variation is even smaller for $\mathrm{D}_{2} \mathrm{O}$. Comparison with the experimental data indicates the calculated frequencies are uniformly exaggerated by some $8 \%$, as is usually the case for SCF data. Indeed, while the frequencies reported in the fourth row, which were calculated using a basis set closer to the Hartree-Fock limit, are generally somewhat lower than ours, they remain considerably larger than the experimental values.

Although the theoretical intensity $A_{1}$ is overestimated by about one order of magnitude in comparison to experiment, the intensities of the other two modes are only slightly too high. Our calculated intensities for all three modes are in excellent coincidence with the values previously obtained by Krohn and Kern (row 4 of Table VI), and essentially duplicated by others. ${ }^{12,13}$ Most importantly, all experimental trends are reproduced with our basis sets: $v_{1}$ is slightly smaller than $v_{3}$; the two most intense modes are correctly predicted to be $v_{2}$ and $v_{3}$.

A similar degree of insensitivity to basis set is observed in the spectroscopic data of $\mathrm{HCl}$, displayed in Table VII. The frequencies calculated with our three basis sets are all within $4 \mathrm{~cm}^{-1}$ of one another. Application of the considerably larger $[7 s 6 p 2 d / 4 s 1 p]$ basis set leads to only a modest reduction in $v$ and little change in the intensity. Our calculated frequency and intensity agree extremely well with the experimental values reported in the last two rows of the table.

All in all, our basis sets appear to reproduce the quantitative aspects of these subunits quite well. Even with use of much larger sets, we do not find significant improvement. Rather, the major portion of the errors, e.g., the overestimation of the frequencies, can be attributed to the omission of electron corelation, a factor which cannot be practically included in our study of the spectrum of the larger complex. Nevertheless, the good quantitative agreement and correct reproduction of experimental patterns in the individual subunits suggest these sets are fully capable of treating the changes induced by complexation.

\section{B. Complex}

Since there appears to be little sensitivity of the spectroscopic data to the specific basis set, we have restricted our investigation of the complex to our best basis, $+\operatorname{VP}^{s}(2 d)^{s}$. The fully optimized SCF geometry of the complex was used as a reference point in computing the normal mode vibrations and intensities. The internal modes of the subunits remain easily identifiable in the complex and it is to these vibrations which we first turn our attention.

Table VIII lists the changes induced in the subunit parameters by formation of the $\mathbf{H}$-bonded complex. The three frequencies of the water subunit are predicted to be virtually
TABLE VIII. Frequency difference $\left(v_{\text {complex }}-v_{\text {monomer }}, \mathrm{cm}^{-1}\right)$ and intensity ratio ( $A_{\text {complex }} / A_{\text {monomer }}$ ) of intramolecular modes resulting from complexation of $\mathrm{H}_{2} \mathrm{O}-\mathrm{HCl}$ and deuterated derivatives calculated with $+\operatorname{VP}^{s}(2 d)^{s}$.

\begin{tabular}{|c|c|c|c|c|c|c|c|c|}
\hline & \multicolumn{6}{|c|}{$\mathrm{HOH}$} & \multicolumn{2}{|c|}{$\mathrm{HCl}$} \\
\hline & $v_{1}$ & $A_{1}$ & $v_{2}$ & $A_{2}$ & $v_{3}$ & $A_{3}$ & $v_{s}$ & $A_{s}$ \\
\hline $\mathrm{H}_{2} \mathrm{O}-\mathrm{HCl}$ & -4 & 1.9 & +1 & 0.9 & -3 & 1.3 & -105 & 6.4 \\
\hline $\mathrm{D}_{2} \mathrm{O}-\mathrm{HCl}$ & -3 & 1.9 & +2 & 0.9 & 0 & 1.2 & -105 & 6.1 \\
\hline $\mathrm{H}_{2} \mathrm{O}-\mathrm{DCl}$ & -4 & 2.0 & 0 & 0.9 & -3 & 1.3 & -75 & 4.9 \\
\hline $\mathrm{D}_{2} \mathrm{O}-\mathrm{DCl}$ & -3 & 1.9 & +2 & 0.9 & 0 & 1.2 & -75 & 4.7 \\
\hline
\end{tabular}

unaffected by complexation, shifting by less than $5 \mathrm{~cm}^{-1}$ in all cases. These small shifts agree nicely with Ayers and Pullin's spectrum of $\mathrm{H}_{2} \mathrm{O}-\mathrm{HCl}$ in an $\mathrm{Ar}$ matrix in which shifts of $20 \mathrm{~cm}^{-1}$ or less were observed. ${ }^{20}$ The insensitivity of the $\mathrm{H}_{2} \mathrm{O}$ frequencies to complexation are entirely consistent with the aforementioned lack of appreciable changes in its geometry.

The effect of complexation upon the intensities is reported as a ratio $A_{\text {complex }} / A_{\text {monomer }}$ in Table VIII. Most affected is the symmetric stretch of water, with $A_{1}$ doubled in magnitude. The increase in the asymmetric stretch $A_{3}$ is predicted to be somewhat smaller while the bend $\boldsymbol{A}_{2}$ undergoes a small decrease. Notice that the above trends are independent of the degree of deuteration. This pattern of complexation-induced intensity modifications (the enhancement of $A_{1}$ is greater than $A_{3}$ while $A_{2}$ is virtually unchanged) does not appear to be unique to the $\mathrm{H}_{2} \mathrm{O}-\mathrm{HCl}$ complex since very similar trends have been noted ${ }^{2,13}$ recently in $\mathrm{H}_{2} \mathrm{O}-\mathrm{HOH}$. We mention finally that the greater sensitivity of the calculated intramolecular intensities to complexation as compared to the frequencies was observed also in our earlier study ${ }^{54}$ of $\mathrm{XH}_{3}(\mathrm{HF})_{n}, \mathrm{X}=\mathrm{N}, \mathrm{P}$.

In contrast to the relative insensitivity of the water internal modes, the $\mathrm{H}-\mathrm{Cl}$ stretch, designated $\boldsymbol{v}_{s}$, is strongly red shifted by formation of the $\mathrm{H}$ bond. This shift is calculated to be $105 \mathrm{~cm}^{-1}$ for $\mathrm{HCl}$ and $75 \mathrm{~cm}^{-1}$ for DCl. This stretching band is also sixfold intensified (nearly fivefold for $\mathrm{DCl}$ ). Such a strong red shift and intensification has been noted on numerous occasions and is characteristic of the $\mathrm{H}$-bonding phenomenon..$^{55}$ In more quantitative terms, Ault and $\mathrm{Pi}$ mentel ${ }^{19}$ have observed a red shift of $216 \mathrm{~cm}^{-1}$ for $\mathrm{H}_{2} \mathrm{O}$ $\mathrm{HCl}$, twice as large as our calculated value of 105 . However, as has been noted on a previous occasion, ${ }^{54}$ the $\mathrm{N}_{2}$ matrix in which they made their measurement is expected to lead to a substantially larger shift than in a vacuum, to which our calculations directly pertain. Taking as an example the similar $\mathrm{Me}_{2} \mathrm{O}-\mathrm{HCl}$ complex for which there exist frequency data both in the gas phase ${ }^{56,57}$ and in $\mathrm{N}_{2}$ matrix, ${ }^{58}$ the shift in the $\mathrm{HCl}$ stretching frequency in $\mathrm{N}_{2}$ is 1.8 times greater than the shift observed in the gas phase. Other factors in the discrepancy between our calculated shift and that observed in $\mathbf{N}_{2}$ include our neglect of correlation, which can have a marked effect on the proton transfer potential and thereby upon the $v_{s}$ frequency, and the invocation of the harmonic approximation. ${ }^{54}$ 
TABLE IX. Frequencies $\left(\mathrm{cm}^{-1}\right)$ and intensities $(\mathrm{km} / \mathrm{mol})$ of intermolecular vibrations calculated with $+\operatorname{VP}^{s}(2 d)^{s}$ basis set.

\begin{tabular}{lcccccccccc}
\hline \hline & $v_{\sigma}$ & $A_{\sigma}$ & $v_{b}$ & $A_{b}$ & $v_{t}$ & $A_{t}$ & $v_{\beta_{1}}$ & $A_{\beta_{1}}$ & $v_{\beta 2}$ & $A_{\beta 2}$ \\
\hline $\mathrm{H}_{2} \mathrm{O}-\mathrm{HCl}$ & 118 & 3 & 459 & 77 & 351 & 38 & 143 & 33 & 94 & 28 \\
$\mathrm{D}_{2} \mathrm{O}-\mathrm{HCl}$ & 114 & 3 & 441 & 53 & 351 & 38 & 109 & 18 & 71 & 15 \\
$\mathrm{H}_{2} \mathrm{O}-\mathrm{DCl}$ & 118 & 3 & 357 & 71 & 252 & 22 & 131 & 25 & 94 & 28 \\
$\mathrm{D}_{2} \mathrm{O}-\mathrm{DCl}$ & 114 & 3 & 331 & 41 & 252 & 22 & 104 & 15 & 71 & 15 \\
\hline \hline
\end{tabular}

Turning now to the intermolecular modes, we adopt the nomenclature of Bertie and Falk. ${ }^{56} v_{\sigma}$ represents the intermolecular stretch which pulls the two subunits apart. Inplane and out-of-plane wags of the proton donor molecule are, respectively, denoted $v_{b}$ and $v_{t}$, whereas $v_{\beta_{1}}$ and $v_{\beta_{2}}$ refer to the corresponding wags of the proton acceptor. While these idealized motions did mix together to some extent, each calculated normal mode was nonetheless readily identified as consisting primarily of one type of motion. These assignments were further confirmed by isotopic substitution.

Owing to the difficulty in detection of bands in the far infrared region, $a b$ initio calculations can play a particularly important role in prediction and interpretation of this portion of the spectrum. The frequencies and intensities calculated for $\mathrm{H}_{2} \mathrm{O}-\mathrm{HCl}$ and its deuterated derivatives with the $+\operatorname{VP}^{s}(2 d)^{s}$ basis set are displayed in Table IX. The frequency of the intermolecular stretch $\boldsymbol{v}_{\sigma}$ is fairly small, between 114 and $118 \mathrm{~cm}^{-1}$, and of very low intensity, only 3 $\mathrm{km} / \mathrm{mol}$. Ault and Pimentel's estimate ${ }^{19,59}$ of $v_{\sigma}(100$ $\mathrm{cm}^{-1}$ ) agrees very well as does the stretching frequency of $119 \mathrm{~cm}^{-1}$ measured for the similar $\left(\mathrm{CH}_{3}\right)_{2} \mathrm{O}-\mathrm{HCl}$ complex in the gas phase. ${ }^{56}$

In all cases, the highest frequency vibrations are predicted to be the in-plane wags of the proton donor $v_{b}$, followed by its out-of-plane counterpart $v_{t}$. Our calculated value of $459 \mathrm{~cm}^{-1}$ for $v_{b}$ in $\mathrm{H}_{2} \mathrm{O}-\mathrm{HCl}$ agrees extremely well with the observation by Ault and Pimentel of a broadband at 460 $\mathrm{cm}^{-1}$ which they also assigned to the $\mathrm{H}$-bond bend. ${ }^{19} \mathrm{Re}-$ placement of $\mathrm{H}$ by $\mathrm{D}$ lowers the calculated frequency, down to $331 \mathrm{~cm}^{-1}$ in the case of full deuteration. This decrease conforms quantitatively to a previous observation ${ }^{56}$ in which replacement of $\mathrm{HCl}$ in $\left(\mathrm{CH}_{3}\right)_{2} \mathrm{O}-\mathrm{HCl}$ by DCl lowered the $v_{b}$ band from 470 to $335 \mathrm{~cm}^{-1}$. The out-of-plane vibration $v_{t}$ is calculated to be $351 \mathrm{~cm}^{-1}$ for $\mathrm{HCl}$ and 252 for DCl. We also note that the in-plane mode is considerably more intense than $v_{t}$. Indeed, with the exception of the greatly enhanced $\mathrm{H}-\mathrm{Cl} v_{s}$ stretch, $v_{b}$ is predicted to be one of the more intense bands of the complex, comparable to the intramolecular modes of $\mathrm{H}_{2} \mathrm{O}$. ${ }^{60}$

The wags of the proton acceptor $\mathrm{H}_{2} \mathrm{O}$ occur at much lower frequency, with $v_{\beta 1}$ surpassing $v_{\beta 2}$ by some $49 \mathrm{~cm}^{-1}$. Our calculated values of 143 and $94 \mathrm{~cm}^{-1}$ for $\mathrm{H}_{2} \mathrm{O}-\mathrm{HCl}$ are consistent with the gas-phase spectrum of $\mathrm{H}_{2} \mathrm{O}-\mathrm{HF}$ in which $v_{\beta 1}$ and $v_{\beta 2}$ are equal to 157 and $64 \mathrm{~cm}^{-1}$, respectively. ${ }^{61}$ The predicted intensities of these two modes are nearly equal to one another and comparable to $A_{t}$ as well as to $A_{1}$, the symmetric internal stretch of $\mathrm{HOH} .{ }^{62}$
We note finally that $\mathrm{A}-\mathrm{H} \cdots \mathrm{B}$ complexes in the gas phase typically show $v_{\sigma}$ frequencies in the range 80-200 $\mathrm{cm}^{-1}$ while $v_{\beta 2}$ is generally below $100 \mathrm{~cm}^{-1}$. ${ }^{4}$ Our calculated values for these quantities fall nicely into these ranges. Summarizing, in view of the flatness of the intermolecular potential and the ensuing anharmonicity of the low-frequency modes, the agreement between our calculated harmonic frequencies and the experimental measurements is indeed encouraging.

\section{SUMMARY AND CONCLUSIONS}

The basis sets which we have used here, containing a diffuse $s p$ shell and two sets of $d$ functions on $\mathrm{O}$ and $\mathrm{Cl}$, provide a solid foundation for investigation of the $\mathrm{H}_{2} \mathrm{O}-\mathrm{HCl}$ complex. Although the polarizabilities of the subunits are underestimated somewhat, as is expected for basis sets of only moderate size, the geometries and electric moments of the subunits agree rather well with experiment. Moreover, our largest $+\operatorname{VP}^{S}(2 d)^{s}$ basis leads to a negligibly small SCF superposition error in the complex (although the MP2 BSSE remains sizable).

Whereas the internal geometry of the $\mathrm{H}_{2} \mathrm{O}$ subunit is essentially unaffected by complexation, the $\mathrm{H}-\mathrm{Cl}$ bond is lengthened substantially. The orientation of the $\mathrm{H}_{2} \mathrm{O}$ molecule with respect to the $\mathrm{O} \cdots \mathrm{Cl}$ axis shows some sensitivity to basis set which can be simply rationalized on the basis of interaction between the various electric moments. Enlargements of the basis set also lead to increased separation between the two subunits, partially explained by a diminishing BSSE. Inclusion of electron correlation shortens the bond and adds about $1 \mathrm{kcal} / \mathrm{mol}$ to the interaction energy which totals 4.7 (with counterpoise correction of both the energy and geometry).

The basis sets used in this study also reproduce with good accuracy all the essential features of the IR spectra of the $\mathrm{H}_{2} \mathrm{O}-\mathrm{HCl}$ complex and its constituent subunits. Upon complexation, the $\mathrm{H}-\mathrm{Cl}$ stretching frequency is red shifted and its intensity enhanced sixfold, conforming to the usual expectations for a $\mathrm{H}$ bond. On the other hand, the spectrum of the $\mathrm{H}_{2} \mathrm{O}$ is affected very little. The intermolecular vibrational modes of highest frequency are the in-plane (459 $\left.\mathrm{cm}^{-1}\right)$ and out-of-plane $\left(351 \mathrm{~cm}^{-1}\right)$ wags of the proton donor $\mathrm{HCl}$. The wags of the proton acceptor and the stretch of the two subunits away from one another fall in the $100 \mathrm{~cm}^{-1}$ range. Calculated intensities of the intermolecular modes vary between 28 and $77 \mathrm{~km} / \mathrm{mol}$, almost as high as the intramolecular vibrations. The only exception is the H-bond stretch $v_{\sigma}$ which is of very low intensity $(3 \mathrm{~km} / \mathrm{mol})$.

This finding conforms to the principle enunciated earlier ${ }^{54}$ that intermolecular vibrations will be of low intensity unless they involve substantial angular reorientation of the dipole moment of either subunit. While the wags of both the proton donor and acceptor cause the necessary dipole reorientation in $\mathrm{H}_{2} \mathrm{O}-\mathrm{HCl}$, the low-intensity $v_{\sigma}$ vibration merely results in an oscillating translation.

\section{ACKNOWLEDGMENTS}

Z. L. expresses his gratitude to Dr. K. Szczepaniak and Professor W. B. Person for many helpful and enlightening 
discussions during a joint stay at the Institute of Molecular Science in Okazaki. Some of the calculations were performed on the SIU Theoretical Chemistry Computer, funded in part by a grant from the Harris Corporation. This work was supported by grants from the National Institutes of Health (GM29391, GM36912, and AM01059) and from the National Science Foundation (DMB-8612768).

${ }^{1}$ T. R. Dyke, Top. Current Chem. 120, 85 ( 1984).

${ }^{2}$ F. G. Celli and K. S. Janda, Chem. Rev. 86, 507 (1986).

${ }^{3}$ R. E. Miller, J. Phys. Chem. 90, 3301 (1986).

${ }^{4} \mathrm{E}$. Knözinger and O. Schrems, in Vibrational Spectra and Structure, edited by J. R. Durig (Elsevier, Amsterdam, 1987), Vol. 16.

${ }^{5}$ A. J. Barnes, in Molecular Interactions, edited by H. Ratajczak and W. J. Orville-Thomas (Wiley, Chichester, 1980), Vol. 1, pp. 273-299.

${ }^{6}$ A. J. Barnes, J. Mol. Struct. 100, 259 (1983); L. Andrews, ibid. 100, 281 (1983); D. J. Millen, ibid. 113, 227 (1984).

${ }^{7}$ J. Howard and T. C. Waddington, in Advances in Infrared and Raman Spectroscopy, edited by R. H. Clark and R. E. Hester (Heyden, London, 1980), Vol. 7, p. 86.

${ }^{8}$ Chemical Applications of Thermal Neutron Scattering, edited by B. T. M. Willis (Oxford University, London, 1973).

${ }^{9}$ (a) R. K. Thomas, Proc. R. Soc. London Ser. A 344, 579 (1975); (b) 325, 133 (1971).

${ }^{10}$ L. A. Curtiss and J. A. Pople, J. Mol. Spectrose. 48, 413 (1973); 55, 1 (1975); 61, 1 (1976).

${ }^{11}$ P. Hobza, H. J. Hofmann, and R. Zahradnik, J. Mol. Struct. 85, 241 (1981); H. Lischka, Chem. Phys. Lett. 66, 108 (1979); P. Hobza, M. M. Szczesniak, and Z. Latajka, ibid. 74, 248 (1980); 82, 469 (1981); P. Hobza, P. Carsky, and R. Zahradnik, Coll. Czech. Chem. Commun. 44, 3458 (1979); D. G. Lister and P. Palmieri, J. Mol. Struct. 39, 295 (1977); J. F. Gaw, Y. Yamaguchi, M. A. Vincent, and H. F. Schaefer III, J. Am. Chem. Soc. 106, 3133 (1984); D. W. Michael, C. E. Dykstra, and J. M. Lisy, J.Chem. Phys. 81, 5998 (1984).

${ }^{12}$ B. A. Zilles and W. B. Person, J. Chem. Phys. 79, 65 (1983).

${ }^{13}$ D. J. Swanton, G. B. Backskay, and N. S. Hush, Chem. Phys. 82, 303 (1983).

${ }^{14}$ S. Chin, T. A. Ford, and W. B. Person, J. Mol. Struct. 113, 341 (1984).

${ }^{15}$ R. Amos, Chem. Phys. 104, 145 (1986).

${ }^{16}$ Y. Bouteiller, M. Allavena, and J. M. Leclercq, Chem. Phys. Lett. 69, 521 (1980); 84, 361 (1981); 99, 432 (1983); J. Chem. Phys. 73, 2851 (1980).

${ }^{17}$ M. M. Szczesniak, S. Scheiner, and Y. Bouteiller, J. Chem. Phys. 81, 5024 (1984).

${ }^{18}$ A. C. Legon and L. C. Willoughby, Chem. Phys. Lett. 95,449 (1983).

${ }^{19}$ B. S. Ault and G. C. Pimentel, J. Phys. Chem. 77, 57 (1973).

${ }^{20}$ G. P. Ayers and A. D. E. Pullin, Spectrochim. Acta Part A 32, 1641 (1976).

${ }^{21}$ A. Schriver, B. Silvi, D. Maillard, and J. P. Perchard, J. Phys. Chem. 81, 2095 (1977).

${ }^{22}$ G. Alagona, E. Scrocco, and J. Tomasi, Theor. Chim. Acta 47, 133 (1978).

${ }^{23}$ J. S. Binkley, R. A. Whiteside, R. Krishnan, R. Seeger, D. J. DeFrees, H. B. Schlegel, S. Topiol, L. R. Kahn, and J. A. Pople, QCPE Prog. No. 406 (1981).

${ }^{24}$ C. Moller and M. S. Plesset, Phys. Rev. 46, 618 (1934); J. S. Binkley and J. A. Pople, Int. J. Quantum Chem. 9, 229 (1975).

${ }^{25}$ P. C. Hariharan and J. A. Pople, Theor. Chim. Acta 28, 213 (1973); Mol. Phys. 27, 209 (1974); M. M. Francl, W. J. Pietro, W. J. Hehre, J. S. Binkley, M. S. Gordon, D. J. DeFrees, and J. A. Pople, J. Chem. Phys. 77, 3654 (1982).

${ }^{26}$ Z. Latajka and S. Scheiner, J. Comput. Chem. 8, 663, 674 (1987).

${ }^{27}$ Z. Latajka and S. Scheiner, J. Chem. Phys. 87, 1194 (1987).

${ }^{28}$ S. F. Boys and F. Bernardi, Mol. Phys. 19, 553 (1970).

${ }^{29}$ P. Hobza, B. Schneider, P. Carsky, and R. Zahradnik, J. Mol. Struct. (Theochem) 138, 377 (1986); J. H. van Lenthe, J. G. C. M. van Duijneveldt-van de Rijdt, and F. B. van Duijneveldt, Advances in Chemical Physics, edited by K. Lawley (Wiley, New York, 1987), Vol. 69, pp. 521-566; M. Gutowski, J. H. van Lenthe, J. Verbeek, F. B. van Duijneveldt, and G. Chalasinski, Chem. Phys. Lett. 124, 370 (1986); S. J. Cole, K. Szalewicz, G. D. Purvis III, and R. J. Bartlett, J. Chem. Phys. 84, 6833 (1986); S. J. Cole, P. G. Burton, and U. E. Senff, ibid. 76, 6073 (1982); W. Meyer, P.
C. Hariharan, and W. Kutzelnigg, ibid. 73, 1880 (1980); M. M. Szczesniak and S. Scheiner, ibid. 84, 6328 (1986); J. M. Leclercq, M. Allavena, and Y. Bouteiller, ibid. 78, 4606 (1983); R. Cammi, R. Bonaccorsi, and J. Tomasi, Theor. Chim. Acta 68, 271 (1985); W. Kolos, ibid. 54, 187 (1980); L. Kurdi, E. Kochanski, and G. H. F. Diercksen, Chem. Phys. 92, 287 (1985); T. L. Mathers and N. R. Kestner, Int. J. Quantum Chem., Quantum Chem. Symp. 19, 297 (1986); A. P. L. Rendell, G. B. Bacskay, and N. S. Hush, Chem. Phys. Lett. 117, 400 (1985); B. H. Wells and S. Wilson, Mol. Phys. 57, 421 (1986); S. Roszak, W. A. Sokalski, P. C. Hariharan, and J. J. Kaufman, Theor. Chim. Acta 70, 81 (1986); S. M. Bachrach and A. Streitwieser, Jr., J. Am. Chem. Soc. 106, 2283 (1984).

${ }^{30} \mathrm{M}$. R. Peterson and R. A. Poirier, Monstergauss, Department of Chemistry, University of Toronto, Toronto, Canada.

${ }^{31}$ E. B. Wilson, C. J. Decius, and P. C. Cross, Molecular Vibrations (Dover, New York, 1980)

${ }^{32}$ K. P. Huber and G. Herzberg, Molecular Spectra and Molecular Structure (Van Nostrand Reinhold, New York, 1979), Vol. IV.

${ }^{33}$ S. A. Clough, Y. Bears, G. P. Klein, and L. S. Rothman, J. Chem. Phys. 59, 2254 (1973).

${ }^{34} \mathrm{~J}$. Verhoeven and A. Dymanus, J. Chem. Phys. 52, 3222 (1970).

${ }^{35}$ I. G. John, G. B. Bacskay, and N. S. Hush, Chem. Phys. 51, 49 (1980).

${ }^{36}$ F. H. DeLeeuw and A. Dymanus, J. Mol. Spectrosc. 48, 427 (1973).

${ }^{37}$ A. D. McLean and M. Yoshimine, J. Chem. Phys. 47, 3256 (1967).

${ }^{38}$ J. S. Muenter, J. Chem. Phys. 56, 5409 (1972).

${ }^{39} \mathrm{~K}$. Morokuma and K. Kitaura, in Molecular Interactions, edited by $\mathrm{H}$ Ratajczak and W. J. Orville-Thomas (Wiley, Chichester, 1980), Vol. 1, pp. 21-66; A. P. L. Rendell, G. B. Bacskay, and N. S. Hush, Chem. Phys. Lett. 117, 400 (1985); A. D. Buckingham and P. W. Fowler, Can. J. Chem. 63, 2018 (1985).

${ }^{40}$ D. Feller, C. M. Boyle, and E. R. Davidson, J. Chem. Phys. 86, 3424 (1987).

${ }^{41}$ H.-J. Werner and W. Meyer, Mol. Phys. 31, 855 (1976); G. H. F. Diercksen, V. Kellö, and A. J. Sadlej, J. Chem. Phys. 79, 2918 (1983); G. H. F. Diercksen and A. J. Sadlej, ibid. 75, 1253 (1981); P. K. Mukherjee, T. Minato, and D. P. Chong, Int. J. Quantum Chem. 23, 447 (1983); G. D. Zeiss, W. R. Scott, N. Suzuki, and D. P. Chong, Mol. Phys. 37, 1543 (1979); P. A. Christiansen and E. A. McCullough, Jr., Chem. Phys. Lett. 55, 439 (1978).

${ }^{42} \mathrm{~A}$ very similar analysis was used to explain the geometry of the $\mathrm{H}_{2} \mathrm{~S}-\mathrm{HF}$ complex: U. C. Singh and P. A. Kollman, J. Chem. Phys. 80,353 (1984).

${ }^{43}$ A. C. Legon and D. J. Millen, Chem. Rev. 86, 635 (1986).

${ }^{44}$ B. H. Wells and S. Wilson, Mol. Phys. 50, 1295 (1983); 54, 787 (1985)

${ }^{45}$ B. J. Krohn and C. W. Kern, J. Chem. Phys. 69, 5310 (1978).

${ }^{46}$ R. A. Toth, J. Quant. Spectrosc. Radiat. Transfer 13, 1127 (1973); C. W von Rosenberg, H. H. Pratt, and K. N. C. Bray, ibid. 10, 1155 (1970); M A. Hirshfeld, J. H. Jaffe, and G. Ross, ibid. 6, 311 (1966).

${ }^{47}$ (a) B. Nelander, J. Chem. Phys. 69, 3870 (1978); (b) R. M. Bentwood, A. J. Barnes, and W. J. Orville-Thomas, J. Mol. Spectrosc. 84, 391 (1980).

${ }^{48} \mathrm{C}$. Camy-Peyret and J.-M. Fland, in Molecular Spectroscopy; Modern Research, edited by K. Narahari Rao (Academic, London, 1985).

${ }^{49}$ W. S. Benedict, W. Gailer, and E. K. Plyler, J. Chem. Phys. 24, 1139 (1956).

${ }^{50}$ A. D. McLean and G. S. Chandler, J. Chem. Phys. 72, 5639 (1980).

${ }^{51}$ T. Shimanouchi, Tables of Molecular Vibrational Frequencies, Natl. Stand. Ref. Data Ser., Natl. Bur. Stand. No. 39 (National Bureau of Standards, Washington, D.C., 1972), Vol. 1.

${ }^{52}$ K. Szczepaniak and W. B. Person, J. Mol. Struct. 80, 309 (1982); W. B. Person, in Matrix Isolation Spectroscopy, edited by A. J. Barnes, W. J. Orville-Thomas, A. Müller, and R. Gaufres (Reidel, Dordrecht, 1981), pp. 415-445.

${ }^{53}$ D. R. Stull and J. Prophet, JANAF Thermochemical Tables, Natl. Stand. Ref. Data Ser., Natl. Bur. Stand. (National Bureau of Standards, Washington, D. C., 1971), Vol. 37.

${ }^{54}$ I. J. Kurnig, M. M. Szczesniak, and S. Scheiner, J. Chem. Phys. 87, 2214 (1987).

${ }^{55} \mathrm{D}$. Hadzi and S. Bratos, in The Hydrogen Bond-Recent Developments in Theory and Experiments, edited by P. Schuster, G. Zundel, and C. Sandorfy (North-Holland, Amsterdam, 1976), Chap. 12.

${ }^{56}$ J. E. Bertie and M. V. Falk, Can. J. Chem. 51, 1713 (1973).

${ }^{57}$ D. J. Millen and O. Schrems, Chem. Phys. Lett. 101, 320 (1983); J. E. Bertie and D. J. Millen, J. Chem. Soc. 1965, 497; J. Lassegues and P. V. Huong, Chem. Phys. Lett. 17, 444 (1972).

${ }^{58}$ A. J. Barnes and M. P. Wright, J. Mol. Struct. (Theochem) 135, 21 (1986). 
${ }^{59}$ Ault and Pimentel were uncertain as to the correct assignment of this frequency in their original work.

${ }^{60} \mathrm{~A}$ shoulder was observed (Ref. 19) in the spectrum at $520 \mathrm{~cm}^{-1}$ whose assignment is particularly nettlesome. Since the composition of the sample was $\mathrm{H}_{2} \mathrm{O}: \mathrm{HCl}: \mathrm{N}_{2}=1: 1: 350$, this feature may well have been due to the water dimer which is competitive with $\mathrm{H}_{2} \mathrm{O}-\mathrm{HCl}$ in stability. Partial sup port of this tentative assignment comes from the observation by Bentwood et al. [Ref. 47(b)] of a band at precisely this frequency for H-bond bend- ing in the water dimer in $\mathrm{N}_{2}$ matrix.

${ }^{6}$ Z. Kisiel, A. C. Legon, and D. J. Millen, Proc. R. Soc. London. Ser. A 381, 419 (1982).

${ }^{62}$ Ault and Pimentel had originally predicted a normal mode at $60 \mathrm{~cm}^{-1}$ based upon the difference between two bands observed at higher frequency. However, since one of the latter probably corresponds to a band of the water dimer rather than $\mathrm{H}_{2} \mathrm{O}-\mathrm{HCl}$, this assignment is highly questionable. 